\title{
Hepatitis A Virus Outbreak in Eastern Ethiopia, 2017: Descriptive Analysis
}

\author{
Desalegn Belay ${ }^{1,}$,, Mikias Alayu ${ }^{1}$, Abiy Girmay ${ }^{2}$ \\ ${ }^{1}$ Center for Public Health Emergency Management, Ethiopian Public Health Institute, Addis Ababa, Ethiopia \\ ${ }^{2}$ World Health Organization Country Office, Addis Ababa, Ethiopia \\ Email address: \\ desalegnpapa@gmail.com (D. Belay),mikiasalayu7@gmail.com (M.Alayu), haddisag@gmail.com (A. Girmay) \\ ${ }^{*}$ Corresponding author
}

\section{To cite this article:}

Desalegn Belay, Mikias Alayu, Abiy Girmay. Hepatitis A Virus Outbreak in Eastern Ethiopia, 2017: Descriptive Analysis. International Journal of Infectious Diseases and Therapy. Vol. 4, No. 3, 2019, pp. 40-43. doi: 10.11648/j.ijidt.20190403.12

Received: March 9, 2019; Accepted: April 15, 2019; Published: September 17, 2019

\begin{abstract}
Hepatitis A virus is a non-enveloped, single-stranded, linear ribonucleic acid (RNA) virus Hepatovirus from the Picornaviridae. It is transmitted by ingestion of food contaminated by fecal matter. Gastrointestinal symptoms with Fever, fatigue, yellowing of the skin or eyes, light-colored feces and dark-colored urine are among symptoms. It is a cause of death for 15000 annually around the globe. The objective of this study is to describe hepatitis A outbreak in in terms of person, place and time. We investigated the outbreak to describe the cases and to identify the etiology. Medical records and line list were reviewed and descriptive data analysis was performed. Serum samples were tested by Immunoglobulin M (IgM) enzyme linked Immunosorbent assay (ELISA) and real time polymerase chain reaction (PCR) methods. We included all 81 cases with acute jaundice syndrome diagnosis and analyzed the data using Microsoft Excel. A total of 81 persons were affected with the acute jaundice syndrome. Among those, 37 (46\%) were females and $44(54 \%)$ were males. The median age of patients was 7 years with range 1-40 years old. The overall attack rate of the outbreak was 27 per 100,000. The age of patients ranged from 1 to 40 years. Out of 18 tested samples, 11 (61\%) were positive for Hepatitis A. From the total cases listed, 44 (45\%) were from the local community and $37(46 \%)$ were from the internally displaced people (IDP). The outbreak lasted from February to August 2017. Hepatitis A was confirmed affecting people below 40 years of ages in Dolo zone, Somali region, Ethiopia in 2017 and there will be no way that it cannot cause illness again.
\end{abstract}

Keywords: Hepatitis A, Virus, Ethiopia

\section{Introduction}

Hepatitis A is a hepatovirus from Picornaviridae family. It is a non-enveloped, single-stranded, linear ribonucleic acid virus. Only a single serotype of hepatitis A virus exists. Hepatitis A is a liver disease caused by the Hepatitis A virus (HAV) which multiplies in the liver and is shed in the feces. Hepatitis A virus can be spread person to person or through contaminated food or beverages. A person can get Hepatitis A by coming into contact with the feces of a Hepatitis A virusinfected person. This can happen when an infected person doesn't wash their hands properly after using the toilet. Some foods can be contaminated during growing, harvesting, or processing, and can cause outbreaks if eaten uncooked or raw. Signs and symptoms may include fever, fatigue, loss of appetite, diarrhea, nausea or vomiting, abdominal pain, yellowing of the skin or eyes, light-colored feces and darkcolored urine. Symptoms of Hepatitis A usually begin 15 to 50 days after a person is infected and range from mild illness lasting 1 to 2 weeks to severe illness lasting months. Some people with Hepatitis A virus infection do not have any symptoms. This is more common in children. There is no specific treatment for Hepatitis A but vaccine [1-4].

The Global Burden of Disease study estimates that in 2013, Hepatitis A virus caused 14, 900 deaths. In the previous years, there has been increase in the number of acute hepatitis A cases from 117 million in 1990 to 126 million in 2005 (and deaths due to hepatitis A to increase from 30,283 in 1990 to 35,245 in 2005). Increased numbers of cases were estimated to occur in the age groups 2-14 years and greater than 30 years. The estimated case fatality ratio 
varies with age. It is $0.1 \%$ among under 15 years children, $0.3 \%$ among persons $15-39$ years of age and $2.1 \%$ among adults aged 40 years and above [4-6].

In outbreak forms, 1,619 people were affected and 495 hospitalized with Hepatitis A virus in Buengkan province in Thailand, 207 people in Taiwan in 2015-2016, 46 cases in Lyon, France in 2017. There has been also an increase in incidence of Hepatitis A virus cases in South Korea from 2004 to 2008 [7-10].

The present investigation took this opportunity to describe the outbreak of hepatitis A virus in terms of person, place and time during the 2017 outbreak in Eastern Ethiopia. The findings from this study will be used to recommend preventive measures for controlling possible future outbreaks.

\section{Methods}

\subsection{Study Area}

The present study was conducted in Dolo zone, eastern most part of Ethiopia. Dollo zone is composed of seven districts (woredas), namely Bokh, Danot, Geladi, Warder, Daratole, Galxamur and yucub. The zonal capital, Warder, is 1,270 kilometers from Addis Ababa, capital of Ethiopia. Based on the 2007 census, the zone has a total population of 306,488 , of whom $43 \%$ are women.

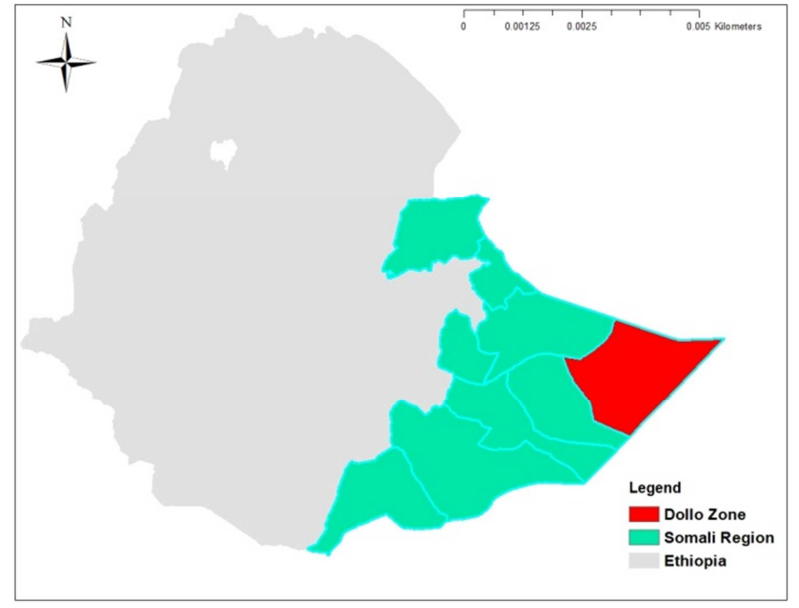

Figure 1. Map of Dolo Zone, Ethiopioa, 2017 (Source: ArcGIS 10.4.1).

\subsection{Study Period and Population}

All cases listed from February to August were included in the study. We obtained the data from the line list collected during the field investigation and patient record reviews from Warder Hospital. Cases were selected based on acute jaundice presentation during hospital visit.

\subsection{Laboratory Investigation and Data Analysis}

Blood samples were collected from 23 patients but 18 were tested. Samples were tested by IgM ELISA and real time PCR in search of Dengue, Yellow fever, Chikungunya, West Nile, Zika, Rift Valley Fever, Crimean Congo
Hemorrhagic Fever, Hepatitis E (only by real time Polymerase Chain Reaction) and Hepatitis A (only by real time Polymerase Chain Reaction) in Institute Pasteur, Dakar as it is a World Health Organization (WHO) reference laboratory for Afro region. We used Microsoft excel to analyze the line list data. Percentages, table and epidemic curve were used to describe this Hepatitis A outbreak in Dolo zone, Ethiopia, 2017.

\subsection{Ethical Consideration}

As this was a response to outbreak, ethical clearance from review board was not needed, but we took verbal consent from patients before sampling. ArcGIS version 10.4.1 was used to locate the area map.

\section{Result}

A total of 81 persons were affected with the acute jaundice syndrome. Among those, $37(46 \%)$ were females and 44 (54\%) were males. The median age of patients was 7 years with interquartile range 11 years old. The overall attack rate of the outbreak was 27 per 100,000; separately it was 25 per 100,000 for males and 29 per 100,000 for females. The age of patients ranged from 1 year to 40 years. The major signs or symptoms that patients presented with were jaundice (all), hepatomegaly $24(30 \%)$, fatigue $29(36 \%)$, itching $5(6 \%)$, bleeding 3 (4\%). Serum sample was collected from 23 patients and 18 were valid and tested for Hepatitis A virus using real time reverse transcriptase polymerase chain reaction real time RT-PCR technique in Institute Pasteur Dakar, Senegal. From the tested samples, 11 (61\%) were found positive for Hepatitis A.

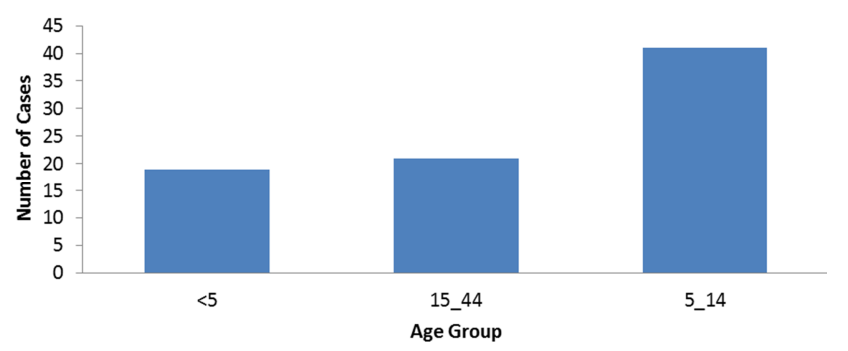

Figure 2. Number of Hepatitis A cases by Age Group, Dolo Zone, Ethiopia, 2017.

Cases were seen in four woredas; $8(9.9 \%)$ were from Danot, 1 (1.2\%) was from Galadi, $31(38.2 \%)$ were from Lahel yucub and 41 (51\%) were from Wardher woredas. From the total cases listed, $44(45 \%)$ were from the local community and $37(46 \%)$ were from the internally displaced people (IDP) due to different local situations.

Table 1. Distribution of HAV cases by Woreda, Dolo Zone, Ethiopia, 2017.

\begin{tabular}{llll}
\hline Woreda & Host & IDP & Total \\
\hline Danot & 0 & 8 & 8 \\
galadi & 0 & 1 & 1 \\
Lahelow yucub & 23 & 8 & 31 \\
Wardher & 21 & 20 & 41 \\
Total (\%) & $44(54 \%)$ & $37(46 \%)$ & $81(100 \%)$ \\
\hline
\end{tabular}


Jaundiced cases were reported from Somali region health bureau since June 2017. However, on record review, similar cases were traced back to February 2017. The outbreak continued until August 14, 2017, the date when the two cases were reported.

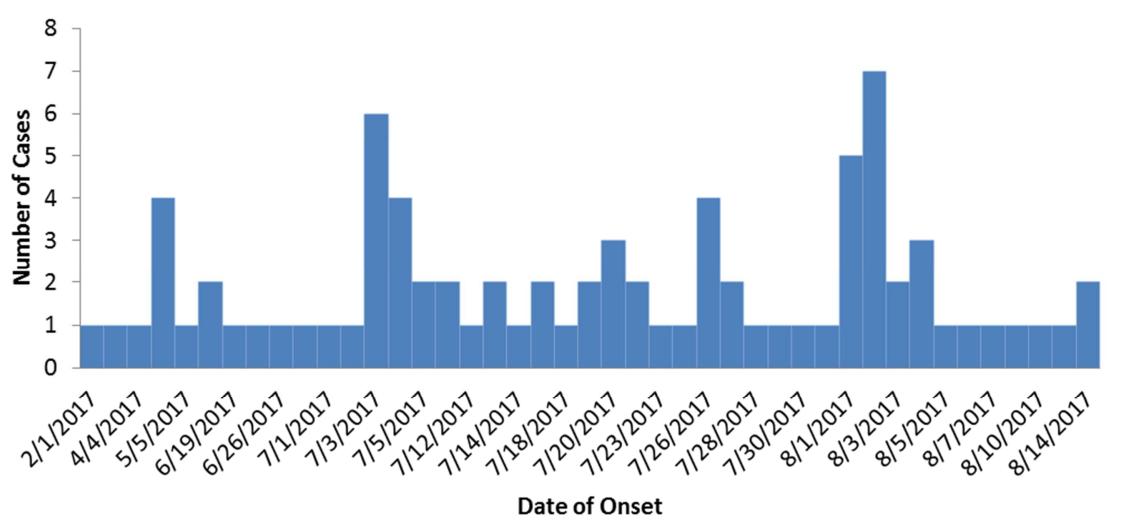

Figure 3. Epi curve showing number of HAV cases by date of onset, Dolo Zone, Ethiopia, 2017.

\section{Discussion and Limitation}

The present study can be indicated as the pioneer for the country in terms viral hepatitis due to hepatitis A virus as to the literature review of the authors. However, as this is a descriptive analysis of the line list data, it is limited to determining the factors that might be associated to the disease. Above all, understanding, epidemic potential and response measures are baseline to implement evidence based national plans to prevent and act against viral hepatitis [11]. Since Hepatitis A viral disease is one of indicators of low socioeconomic status, it can be decreased by increasing income and availability of clean water supply and adequate sanitation [4]. The occurrence of this disease in both the residential population and concentration camps (IDP) is consistent with that happed in Germany among asylum seekers in $2015 / 2016$. This can be explained by sharing of food stuff at some sources between the dwellers or residents and asylum seekers or inadequate sanitation at that specified period of time. It is among the commonest health problems during overcrowding like camps. In obvious reasons, presence of large number of refugees can affect the health system of a country [12-13].

Though, in total, 23 samples were collected and submitted to laboratory, only $18(78 \%)$ were to be tested. This positivity rate concurs with a laboratory result in a Nigerian study which was $77.2 \%$ among primary school pupils [14]. Among the tested ones, nine or half of them were positive for hepatitis A virus by real time reverse transcription polymerase chain reaction (RT-PCR) was applied to confirm.

The occurrence in our study area was much higher than that in Ireland in 2015 which was 0.4 per 100,000 populations. The increasing of cases with age in our study again can also be referenced in line with other previous evidences [15].

Cases were reported in June although the disease had been circulating since February 2017. This is clearly late detection of the disease. It can be clarified that the disease detection ability of the surveillance system is weak or lack of awareness on span of infectious diseases from the health workers side, as expected from most developing countries.

\section{Conclusion}

Hepatitis A was confirmed in Dolo zone, Somali region, Ethiopia in 2017. The disease in this outbreak has affected people with the age of 40 years and below. The number of cases has increased with increasing age of the patients. It has affected four woredas of Dolo zone, namely Danot, Galadi, Lahelow yucub and Warder. The outbreak lasted from February to August 2017 which, in the area, was a rainy season. Generally the detection of the outbreak was late. Improving hygiene and environmental sanitation is crucial to prevent Hepatitis A virus infection in all ages of persons. In order for unusual cases to be detected early, training of health professionals and surveillance officers will play an irreplaceable role. Timely disease detections lead to timely public health response in all instances. Setting up of the national laboratory with all necessary reagents and supplies is also mandatory for early detection, confirmation and response of infectious diseases like hepatitis A. Identifying the risk of acquiring Hepatitis A virus among the communities through sero survey is crucial to set up an emergency preparedness plan against the disease.

\section{Acknowledgements}

We are grateful to Ethiopian Public Health Institute for availing all necessary logistics to conduct the field work during the outbreak investigation. Our gratitude goes to staff of Somali region health bureau, Dolo zone health representatives and administration, Warder Hospital and Warder Woreda health office for the friendly reception and guidance on field. 


\section{Authors Contribution}

The work presented here was carried out in collaboration between all authors. Desalegn Belay collected laboratory specimen, coordinated epidemiological data collection and analyzed the data, coordinated laboratory work and wrote the manuscript. Mikias Alayu collected epidemiological data on field analyzed the data, coordinated laboratory work and wrote the manuscript. Abiy Girmay reviewed the manuscript. All Authors have participated in the interpretation of findings and review of the manuscript. All authors read and approved the final manuscript.

\section{Conflicts of Interest}

All authors declared they have no conflict of interest.

\section{List of Abbreviations}

$\begin{array}{ll}\text { ELISA } & \text { Enzyme Linked Immunosorbent Assay } \\ \text { HAV } & \text { Hepatitis A Virus } \\ \text { IDP } & \text { Internally Displaced People } \\ \text { IgM } & \text { Immunoglobulin M } \\ \text { PCR } & \text { Polymerase Chain Reaction } \\ \text { WHO } & \text { World Health Organization }\end{array}$

\section{References}

[1] Disease CD of PHD of C, Foodborne Control. Foodborne Hepatitis A Fact Sheet. 2017. p. 1-2.

[2] WHO S. Hepatitis A. 1988. p. 1-3.

[3] WHO. Technical considerations and case definitions to improve surveillance for viral hepatitis: technical report. 2016. $22 \mathrm{p}$.

[4] WorldHealthOrganization. Position paper, Hepatitis B. Wkly Epidemiol Rec. 2012; 84 (28): 261-76.
[5] Linder KA, Malani PN. Hepatitis A. Jama [Internet]. 2017; 318 (23): 2393. Available from: http://jama.jamanetwork.com/article.aspx?doi=10.1001/jama. 2017.17244

[6] Control YCD. Hepatitis A. 2016. 3 p.

[7] Poovorawan K, Chattakul P, Chattakul S, Thongmee T, Theamboonlers A, Komolmit P, et al. The important role of early diagnosis and preventive management during a largescale outbreak of hepatitis A in Thailand. Pathog Glob Health. 2013; 107 (7): 370.

[8] Chen N, Liu Z, Shie S, Chen T, Wu T. Clinical characteristics of acute hepatitis A outbreak in Taiwan, 2015 - 2016: observations from a tertiary medical center. BMC Infect Dis. 2017; 17 (441): 4.

[9] June J, Charre C, Ramière C, Chidiac C, Zoulim F, Koffi J, et al. Hepatitis A outbreak in HIV-infected MSM and in PrEPusing MSM despite a high level of immunity, Lyon, eurosurveillance. 2017; (June): 1-4.

[10] Seo JY, Seo JH, Kim MH, Ki M, Park HS, Choi BY. Pattern of Hepatitis A Incidence According to Area Characteristics Using National Health Insurance Data. J Prev Med Public Heal. 2012; 45 (3): 167.

[11] WHO A. END HEPATITIS BY 2030. 2017. p. 13.

[12] Michaelis K, Wenzel JJ, Stark K, Faber M. Hepatitis A virus infections and outbreaks in asylum seekers arriving to Germany, September 2015 to 2016. Emerg Microbes Infect. 2017; 6 (September 2016): 3.

[13] Hassan-kadle MA, Osman MS, Ogurtsov PP, Hassan-kadle MA, Petrovich P. Epidemiology of viral hepatitis in Somalia : Systematic review and meta-analysis study. 2018; 24 (34): 3927-57.

[14] Ibrahim A. Hepatitis A Virus Infection among Primary School Pupils in Potiskum, Yobe State, Nigeria. IntJCurrMicrobiolAppSci. 2015; 4 (4): 948-54.

[15] Ireland. Hepatitis A. 2015. p. 1-10. 